the

TRANS $\cdot \mathrm{N}^{\circ}{ }^{\circ} \cdot 200 \mathrm{I}$

ARTICULOS $\cdot 91-102$
Cuando se aplican las categorias de código, emisor, receptor y contexto a la comunicación lingüistica, éstas son más complejas de lo que pudiera parecer a primera vista. La dificultad se acrecienta cuando se analizan en una obra literaria, y más aún cuando se trata de una obra literaria traducida a otra lengua $y_{\text {, }}$ por ende, a otra cultura.

Estas categorias deben ser entendidas desde una perspectiva social, desde los grupos de hablantes en contextos particulares, que negocian el significado de sus locuciones a partir de información adquirida culturalmente. El no tener acceso a tal información o el situarla desde coordenadas culturales distintas puede ocasionar distorsiones en el mensaje, errores o falta de comprensión no sólo de lo que se dice sino de lo que se quiere decir.

\title{
A propósito de la homogeneidad de algunas categorías del proceso de comunicación
}

Beatriz Giudicl Fernández IES “La Magdalena», Avilés, Asturias
When applied to linguistic communication, the categories of code, sender, receiver and context are much more complex than expected. When studied in a literary text, this complexity increases and becomes bigger indeed in the case of a literary text translated into another language, and consequently, into another culture.

Both in natural and in literary speech, these categories have to be understood from a social perspective, a social matrix (cf. Hymes), that is to say, from porticular groups of speakers in specific situations, who negotiate meaning by means of a knowledge acquired in the social group they belong to. To lack this information or place it within alien nets may lead to distortions of meaning, mistakes or lack of understanding 
El esquema básico de la comunicación en general y de la comunicación lingüistica en particular está constituido por un emisor, un mensaje y un receptor, a los que se suman elementos tales como un código, un canal y un referente. El emisor es quien envía el mensaje, el receptor, quien lo recibe y descodifica, el código, un sistema de señales con sus correspondientes reglas de combinación, el canal, el soporte físico de la transmisión del mensaje (radio, letra impresa, etc.), y el referente, la realidad verbal o susceptible de ser verbalizada, que el destinatario comprende. La comunicación literaria constituye un tipo concreto de comunicación, en el que el emisor es el autor de la obra, el receptor o destinatario es el lector y el mensaje es la obra en sí. Además, tanto la comunicación lingüística como la literaria usan un conjunto limitado de elementos y leyes de combinación capaces de producir una serie ilimitada de operaciones, es decir, una lengua. Ahora bien, el mensaje o significado de la obra literaria no está representado por el valor referencial de los signos lingüísticos que la constituyen ni por el valor semántico de las palabras, sino que se origina «al poner en relación determinados hechos del texto con realidades y conceptos exteriores creando redes de significación coherentes" (Bobes 1974:223). El proceso de la comunicación literaria debe entenderse como expresión (acción del emisor-autor) y como interpretación (acción del receptor-lector) y «sólo así, y sobre las posibilidades del sistema de signos que utiliza, se podrán interpretar los signos literarios» (Bobes: I990:64-65).

En el caso de una obra literaria traducida, el esquema básico antes aludido se complica todavía más, ya que el emisor es, en realidad, el autor-traductor, el receptor, el lector-lector de la traducción, y el mensaje, una obra literaria traducida, es decir, un texto vertido a otra lengua $y$, lo que es más importante puesto que aporta una mayor complejidad a la hora de la interpretación del mensaje, a otra cultura.
En este artículo intentaremos ver qué ocurre cuando las categorías del modelo abstracto de comunicación son empleadas para analizar un tipo especial de comunicación, cual es la comunicación literaria en una obra traducida, e intentaremos demostrar que dichas categorías son, en realidad, mucho más complejas de lo que a primera vista pudiera parecer, aunque nos centraremos solamente en el código, el emisor y el receptor. Sin embargo, como nos recuerda con acierto Valentín García Yebra, no se traduce de lengua a lengua, sino de babla a habla, es decir, de un texto a otro, de una comunidad lingüística a otra (García Yebra 1989:36), analizaremos asimismo el concepto de contexto con el objetivo de estudiar si también constituye una categoría igualmente compleja cuando se trata de entender y desambiguar mensajes literarios traducidos. Para ello se analizarán ejemplos extraidos de: Aventura de un fotógrafo en $L a$ Plata, de Adolfo Bioy Casares, El informe de Brodie, de Jorge Luis Borges, Historias de cronopios y de famas, de Julio Cortázar, Sobre héroes y tumbas, de Ernesto Sábato, No babrá más penas ni olvido, de Osvaldo Soriano, e Historia del Triste, de Horacio Vázquez Rial, así como sus respectivas traducciones al inglés, italiano y francés.

\section{CÓDIGO(S)}

La lengua natural comunica más que información y pensamiento (Fasold 1984) pues es el archivo adonde ban ido a parar las experiencias, saberes y creencias de una comunidad (Lázaro Carreter 1997:I9) y lo mismo ocurre con la lengua literaria. Por ejemplo, recibimos información cuando leemos: Empezamos la construction un domingo por la tarde (HCF:33) - cuando se nos dice en La aventura de un fotografo on La Plata (AFLP:I3) que la pensión de Juan Almanza quedaba en las calles 2 y 54 (en la ciudad de La Plata las calles tienen 
número, como en Nueva York). Igualmente ocurre cuando leemos en Sobre héroes y tumbas que dos personajes se sentaron a una mesa que daba al Paseo Colón (SHT:Iro). Pero este texto comunica algo más, que no está en el texto y que se le escapa al lector de la traducción (cuando no también al traductor), que sólo detecta información, porque el Paseo Colón es un lugar de bares de mala fama como el Volga o el Unión, hoy desaparecidos, una calle donde mamá dice que no deben ir los niños solos (Cortázar 1970:Io9), y donde, según el tango Sentimiento Gaucho (Caruso y Canaro 1924), van los que tienen perdida la fe. Además, sabe que el Paseo Colón corre paralelo al Río de la Plata, y estos personajes son dos seres a la deriva. Esta información extra que le llega al lector nativo se debe al hecho de que el lenguaje natural y el literario deben ser entendidos desde una perspectiva social, desde grupos de hablantes concretos en contextos particulares. $\mathrm{O}$, como dice Hymes, desde una matriz social (Hymes I974), pues son los grupos de hablantes en contextos particulares los que activan esa información extra y utilizan el código lingüístico para dar más información que la que se extrae en un primer nivel de comprensión. Un caso extremo de lo que acabamos de decir lo constituye un tipo de texto no cohesionado pero coherente gracias a esa otra información que llega a través del código. En la lengua natural un diálogo del tipo:

A: ¿Qué hora es?

B: Tu hermana acaba de irse a trabajar.

permite a $A$ saber que son las nueve de la mañana porque esa es la hora en que su hermana sale para el trabajo. En casos como este es la información que está fuera del texto lo que lo cohesiona y lo hace comprensible hasta el punto de permitir una comunicación total. Lo mismo ocurre con el discurso literario. En El informe de Brodie leemos:
Te doy veinticuatro horas para que lo pensés bien, cn el calabozo. No te voy a apurar. Si no querés entrar en razón, ite [sic] haciendo a la idea de un descansito en la calle Las Heras. Como es de imaginarse, yo no entendi (EIB:42-43).

El protagonista de este cuento, "La historia de Rosendo Juárez», no entiende que el comisario lo está amenazando con mandarlo a la cárcel porque no sabe que en la calle Las Heras hay una penitenciaría. La ignorancia de esta información externa al texto le impide comprender la amenaza. En un texto literario, cohesionado o no, puede ocurrir que haya dos niveles de significación: uno superficial y otro profundo, que es lo que da sentido no a lo que se dice sino a lo que se quiere decir, como se ve en el ejemplo citado.

En el caso de una traducción literaria tenemos dos códigos lingüísticos (la lengua origen y la lengua meta), empleados por hablantes que, para negociar el significado de sus locuciones y, en este caso, de sus lecturas, parten de una serie de presupuestos adquiridos culturalmente. Así, al lector de la traducción puede ocurrirle lo que al protagonista del cuento citado: no entender. Mejor dicho, el lector italiano y el francés se encuentran en esta posición, mientras que el lector inglés, al leer la expansión Las Heras-the penitenciary (DBR:47) sabe de qué lugar se trata. Lo que de ninguna manera puede saber, a no ser que haya vivido en Buenos Aires y esté muy familizarizado con la historia de la ciudad, es que la penitenciaría aludida por el comisario es la antigua Penitenciaría Nacional, inaugurada en 1877 y demolida cuando la ciudad, al crecer, la atrapó en sus límites. Desconocerá, asimismo, la existencia de algún que otro túnel, excavado por los presos y descubierto poco después de la demolición del edificio, hecho que provocó la sonrisa cómplice de muchos porteños.

También puede suceder que el lector foráneo reciba un mensaje distorsionado, al encajar el mensaje en los elementos sociales de su código

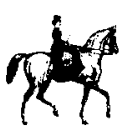

93 
lingüistico y cultural. Cuando el lector inglés se encuentra con: The only person I've seen with breeches and leather leggins in the whole county of Las Flores (AFLP:I9) (La unica persona que be visto en briches y polainas de cuero, en todo el partido de Las Flores AFLP:27), no detecta nada anómalo, pues para él es normal que una persona que vive en el campo use breeches. No así para el lector argentino, que sabe que el hombre de campo en Argentina e incluso los grandes hacendados usan bombachos o pantalones y botas de cuero o zapatillas. Este lector es el único que comparte la ironía del autor hacia un personaje que quiere hacerse el inglés. Es más, puede incluso llegar a entender que un personaje así vestido es un snob o un recién llegado a la burguesía argentina ligada a la propiedad de la tierra.

Todo lo anteriormente dicho a propósito del código se puede aplicar al subcódigo, entendiéndose por tal un léxico específico que permite comprender los significados connotativos que tal léxico lleva implícitos. Esto es lo que ocurre con la forma de hablar de Humberto D'Arcángelo en Sobre béroes y tumbas y con la manera de hablar que Borges da a sus personajes en El informe de Brodie, por ejemplo. Humberto D'Arcángelo es hijo de un inmigrante italiano y no habla correctamente el castellano, como se ve en los siguientes ejemplos, en los que subyacen estructuras de la lengua italiana: Propio la basura (SHT:35), traducido como real garbage (OHT:30), proprio una merda (SET:27), une belle saloperie (A:24), aqui a este pai bay que avivarse (SHT:Ior), que se traduce como People in this country have to wake up (OHT:93), Qui in questo paese bisogna farsi furbi (SET:80), faut maintenant que ce pays se réveille (A:8I), y ¿̇se iria en Italia? (SHT:164), que aparece como would you go back to Italy? (OHT:I5I), se ne andrebbe, patre, in Italia? (SET:I24), t'y retournerais en Italie? (A:I30). En «La historia de Rosendo Juárez», de El informe de Brodie, leemos expresiones del tipo: Usted no me conoce más que de mentas (EIB:40), traducido como You don't know me except maybe by reputation (DBR:44), Lei non mi conosce che di nome (TLO:385), Vous ne me connaissez que de nom (LRB:39), el finado Paredes (EIB:40), que aparece como the late Paredes (DBR:44), Paredes buon'anima (TLO:385), Feu Paredes (LRB:40), la Casilda (EIB:45), que se traduce como Casilda (DBR:48), la Casilda (TLO:389), la Casilda (LRB:45), o los forasteros (EIB:47), traducido como these strangers (50), iforestieri (TLO:390), des gens venus d'ailleurs (LRB:47). Los lectores de la traducción inglesa, italiana o francesa no tienen modo de saber cómo habla Humberto D'Arcángelo puesto que las locuciones de este personaje son neutralizadas en la lengua meta, donde se mantiene el mensaje pero se pierden las variantes dialectales o de habla presentes en el texto original. Estas variantes constituyen un subcódigo cargado de información para el lector nativo, quien identifica la procedencia de D’Arcángelo (Italia), su extracción social, y su nivel cultural, caracterizado, entre otras cosas, por un uso incorrecto de la lengua castellana. En el caso de "La historia de Rosendo Juárez", una de las características más sobresalientes de este cuento es el lenguaje empleado por el personaje. Se trata de forma de hablar más típica del campo que de zonas urbanas, donde por ejemplo, se diría $U_{\text {sted }}$ me conoce sólo de nombre o los extranjeros, en vez de conocer más que de mentas o forasteros. Posiblemente se trate también de una forma de hablar común hace unos cuantos años y hoy caída en desuso.

\section{EMISOR-RECEPTOR}

Según el esquema básico de la comunicación en general o de la comunicación lingüística en particular, se tiende a considerar al emisor y al receptor del mensaje como elementos homogéneos. Si bien esto es útil a la hora de confeccionar un modelo teórico, creemos que presenta dificultades cuando lo empleamos para analizar 
al emisor y al receptor de un mensaje literario en particular, y más aún si es un mensaje literario traducido. Nos encontramos con un emisor y un receptor en concreto, que pertenecen a una comunidad lingüística determinada, entendiéndose por tal no un grupo humano que interactúa a través del lenguaje (Bloomfield, en Hudson 1980), sino una comunidad que comparte el conocimiento de las reglas para producir e interpretar el mensaje (Hymes 1974:52). En el caso de las obras analizadas en este trabajo, el emisor es un escritor argentino (porteño, para ser más preciso) y el receptor es el lector argentino. Ambos han nacido en un país, y comparten unas coordenadas culturales, históricas, léxicas, políticas, etc., que les permiten comunicarse y entenderse más allá de las palabras. Sólo quien comparta esas mismas coordenadas será capaz de percibir la ironía de Sábato cuando describe a los snobs de apellidos compuestos reunidos en una casa de modas ( $S i$ en este país vos te llamás Vignaux, aunque tu abuelo baya sido carnicero en Bayona o en Biarritz, sos bien. Pero si sobrellevás la desgracia de llamarte De Ruggiero, aunque tu viejo baya sido un profesor de filosofía en Nápoles, estás refundido, viejito; nunca dejarás de ser una especie de verdulero SHT:232) o compartir las tristezas del cronopio Cortazar en la calle Corrientes (Una multitud de famas que remota Corrientes a las once y veinte HCF:ro9), calle que suben los amantes del boxeo después de haber asistido a un combate en el Luna Park, calle de peregrinación desde los barrios al centro, pues Corrientes es el centro, calle de cabarets y salones donde el tango empezó a adecentarse y que vio pasar el cortejo fúnebre de Carlos Gardel y el de Eva Perón. De ahí que si el emisor 2, es decir, el traductor, $y$ el receptor 2, es decir, el lector de la traducción, no comparten dichas coordenadas, se quedarán en un primer nivel incompleto de comprensión. La comprensión total de los textos les estará vedada porque, si es cierto que recordamos culturalmente (Steiner 1976:29), también lo es que entendemos culturalmente.

El receptor nativo tampoco es un elemento homogéneo. No existe un único receptor, un receptor ideal, que capta todos y cada uno de los mensajes del emisor. Ya no se trata de pertenecer a la misma comunidad lingüística del emisor y compartir unas coordenadas históricas, geográficas o culturales a secas. Volviendo al tema del contexto cultural que sirve de marco a la comunicación emisor-receptor, habría que agregar que hay otros elementos tales como la socialización, la sensibilidad ante la realidad, la edad, etc., que nos permiten catalogar distintos tipos de lectores nativos. El lector argentino de una cierta edad, preocupado por la soberanía nacional, indignado ante la entrega de los recursos naturales como el petróleo a compañias extranjeras, especialmente norteamericanas, posiblemente entenderá qué quiere decir Sábato con los Banqueros desencadenan sus Guerras por el Petróleo (SHT:30). Aquel que reconozca los ejemplos de tilinguería en Sobre béroes y tumbas por ser consciente de este aspecto de la sociología nacional, o que se reconozca en ellos, acaso entienda la sorna del autor en el ejemplo de los apellidos (ver párrafo anterior). Quien no lo haga o no quiera hacerlo será un lector que se quedará con algo anecdótico de la trama de la novela. $Y$ al lector que emplee un registro en el que sólo tiene cabida el tú, le pasará inadvertida la reprimenda de don Marcos al Triste ('Si, me estâs amenazando': el paso al tuteo fue el primero que Cristóbal dio en falso aquel dia $\mathrm{HT}: 56$ ). Puede incluso sacar una conclusión errónea del desafortunado uso de un código informal en ese contexto.

Si arrojamos una piedra a un estanque, veremos que se forman ondas sucesivas, causadas por la energía liberada por el impacto. Esta radiación se transmite sobre la superficie del agua en forma de ondas, que se van haciendo más amplias a medida que la energía liberada se debilita. Esta imagen resulta muy útil para explicar los distintos tipos de lectores nativos.

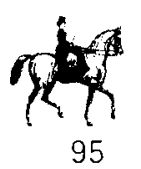




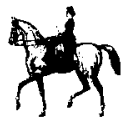

La primera onda, la más cercana a la piedra, estaría formada por aquel lector posiblemente coetáneo del escritor, hijo de inmigrantes, socializado hasta el punto de entender el significado de como el guarani para las señoras (EIB:87), sensible a la realidad política del país desde la década de 1930 más o menos, y quizá desencantado oyente de tangos. Este sería el lector total. Luego, tendríamos al lector perteneciente a la primera o segunda generación de hijos de inmigrantes, igualmente sensible a esa realidad, pero alejado en el tiempo de ciertas referencias históricas (por ejemplo, la huelga grande, en SHT:498, o el discurso del comisario en NHMPO:65), de ciertos ritos sociales como los velatorios de antes, o de la conexión entre algunos tangos o letras de murgas (comparsas) en Sobre béroes y tumbas con el desarrollo de la trama, lo cual le restaría capacidad de comprender el mensaje en su totalidad. Este sería el lector intermedio. Por último, nos encontraríamos con un lector argentino joven o mayor, de espaldas a la realidad del país; un lector que, aunque socializado para entender que un tal Wilson Nerva es lógicamente uruguayo (HT:129) o que los domingos se comen ravioli ( $\mathrm{HCF}: 33$ ), es incapaz de leer una novela como No babrá más penas ni olvido y verse reflejado en la burla cruel que el autor, Osvaldo Soriano, hace de la historia argentina reciente, pues nadie quedó al margen de la misma; ni siquiera los que decían estarlo. Este sería el lector minimo.

$\mathrm{Si}$, como se ha visto, el lector nativo no pertenece a una categoría homogénea, cabe preguntarse qué ocurre con el lector de una traducción. ¿Hay un único lector 2? ¿Todos los lectores pierden la misma información, y la misma cantidad y calidad de información? ¿El lector italiano pierde menos información que el inglés o el francés? Salvo excepciones, es poco probable encontrar un lector extranjero que pueda pertenecer a la categoría de lector total. Esto sólo sería posible si dicho lector hubiera vivido en Argentina, hubiera entendido al país y fuera, por lo tanto, capaz de descifrar los mismos mensajes que el lector nativo total. Es más probable que la mayoría de los lectores de las traducciones de literatura argentina pertenezcan a las dos categorías restantes: lector intermedio y lector minimo. Independientemente de su nacionalidad, el lector intermedio sería una persona de una determinada edad, hecho que le permitiría entender ciertas alusiones históricas como, por ejemplo, las referidas a la época peronista y los comentarios acerca del tango en Sobre béroes y tumbas, así como de una determinada sensibilidad social, que haría posible que este lector comprendiera los comentarios acerca de la política del gobierno de Perón con respecto a los refugiados nazis en Argentina (Yo lo saqué de Alemania cuando estábamos a punto de perder la guerra, le consegui documentos argentinos y le di empleo HT:Io5) o la velada alusión a la Ley de obediencia Debida (Pero te pueden obligar; no, Chaves, no nos pueden obligar: a vos tampoco HT:I64). El lector minimo sería el lector que se queda con poco más que la anécdota de la trama, incapaz de captar ninguna, o prácticamente ninguna, connotación histórica, cultural, idiomática -cuando no se queda con una versión totalmente distorsionada de la misma, como es el caso de la traducción al japonés de El túnel, que ya desde el título induce al error: Mitología del amor moderno, o el de la versión francesa de Sobre béroes y tumbas: Alejandra. Sin comentarios.

\section{CONTEXTO}

Hymes señaló que no podemos tomar la forma lingüística, el código, ni siquiera el habla, como marco de referencia para analizar el lenguaje. Para él, lo que hay que analizar son los grupos de hablantes y las funciones del lenguaje empleadas por ellos en contextos particulares, ya que el lenguaje debe estudiarse desde la perspectiva de quién dice algo a quién, dónde, para qué y cómo. Estos interrogantes tienen 
contestación y sentido dentro de la cultura que los hace pertinentes, pues es precisamente el contexto de cultura (Malinowsky, Firth) la clave para desambiguar la comunicación lingüística natural y literaria. En ambos casos, ese contexto cultural se manifiesta en los diversos códigos de referencias sobre las que se proyecta el elemento a descifrar, desde el retórico al filosófico, pasando por el idiolectal o el histórico, por citar unos pocos.

De alguna manera, todo esto es exterior a la obra literaria, por lo que algunos autores prefieren emplear el término extratexto, aunque no todos lo hacen como sinónimo de lo mismo. Para algunos, como Genot, se trata de la ideología o cultura de una época; para otros, como Lotman, son los códigos artísticos, formados históricamente (Marchese/Forradellas I986:I58-159). En este trabajo se usará el concepto de intertextualidad como sinónimo de códigos externos al texto como tal; aunque aquellos se concreten en este de una u otra manera (Krysinski 1997). También se entenderá contexto como sinónimo del esquema mental de situaciones, ritos, etc. que permite entender un texto y predecir tipos de comunicación. Algunos de estos esquemas son comunes a la humanidad; otros están condicionados por una cultura específica. Esto se ve muy bien en una conversación donde se narre una boda, por ejemplo. Un lector inglés esperará oir que la novia lleva algo azul, algo nuevo, algo viejo y algo prestado; un lector castellano-hablante, una descripción del vestido de novia -blanco-, de las flores que adornan la iglesia, etc. El texto se entiende porque está enmarcado en un contexto, entendido como situación social conocida por cada lector. Pero en el momento en el que aparezca en la descripción de la boda un elemento insólito para la cultura a la que el texto pertenece, se producirá un cortocircuito, y esto limitará o impedirá la comprensión. Algo parecido ocurre en un texto literario. Cuando uno de los personajes de Sobre béroes y tumbas, dice en el café La Helvética: Lo que es el miedo al pueblo (SHT:155), a propósito de una conversación que acaba de mantener con un representante del Partido Comunista Argentino, el lector argentino tiene la clave para entender la crítica que encierra dicho comentario, a saber, el apoyo de este partido a la alianza electoral en torno al candidato opositor a Perón, apoyado por la oligarquía argentina y la jerarquía eclesiástica, mientras que el lector de la traducción inglesa, italiana o francesa, a menos que esté muy politizado o sea estudioso de historia argentina contemporánea, se quedará perplejo porque se le escapará el sentido del mencionado comentarjo. O le resultará intrascendente.

En otras ocasiones, la información extratextual podrá dar lugar a una distorsión del mensaje original. El lector inglés que se encuentre con: At the counter, beneath the petty-bourgeois smile of the queen, ... British managers and upper level excutives were downing their gin or their whisky and laughing at each other's jokes. The Pearl of the Crown, be thought (OHT:139) (En el mostrador, bajo la sonrisa pequeñobuerguesa de la reina, ... gerentes y altos empleados ingleses tomaban un gin o su wbisky y reian de sus cbistes. La Perla de la Corona, pensó (SHT:I5I). Este comentario que Martín hace de Alejandra confunde al lector inglés, que identifica a la India como la perla de la corona británica. También puede creer que hay una fotografia de la India en alguna pared o establecer cualquier otra conexión siempre sobre la base de: India-Perla de la Corona. En cualquier caso estaría en un error. Sólo el lector argentino es capaz de entender la metáfora y recoger el guiño que le hace el autor. En una primera interpretación identificaría la metáfora con que el autor alude a la belleza de la joven; en una segunda, asociaría Argentina=Perla de la Corona. ¿Por qué? Porque en la década de r93o la Argentina era una semicolonia británica, como lo demuestran las siguientes palabras de Guillermo Leguisamón, funcionario argentino nombrado Sir por 
los servicios prestados a los ferrocarriles, británicos of course, en Argentina:

La Argentina es una de las joyas más preciadas de la corona de su Graciosa Majestad (González 1986:24).

En ocasiones, el concepto de contexto puede resultar ambiguo, ya que se usa para referirse a la situación real en la que se desarrolla un texto, es decir, lo que Firth llama context of situation, $O$ como sinónimo de lo que la lingüística sajona denomina co-text (Catford), es decir, el medio lingüístico inmediato. De todos modos, no puede hablarse de una separación tajante entre estas dos acepciones, ya que hay veces en las que incluso las relaciones co-textuales se vuelven significantes gracias a información contextual extratextual. Así ocurre, por ejemplo, en $L a$ aventura de un fotógrafo en La Plata, cuando el protagonista, Juan Almaza, va a una casa para un encuentro amoroso y ve sobre la mesa un gato de porcelana, de color lila y de tamaño natural. Leemos a continuación: Este adorno le trajo un recuerdo que se esfumó antes de aclararse $y$ que por un momento le dejó nostalgias (AFLP:I06). El valor deíctico, anafórico, de este en este adorno se entiende por la referencia al gato de porcelana que aparece en la oración inmediatamente anterior. Pero, a su vez, la clave para entender un recuerdo que se esfumó antes de aclararse y que por un momento le dejo nostalgias proviene de un elemento extratextual como es el tango A media luz (Lenzi y Donato I925), que dice:

\footnotetext{
Corrientes tres-cuatro-ocho, segundo piso ascensor.

No hay porteros ni vecinos, adentro, cocktail y amor...

Pisito que puso Maple, piano, estera y velador, un telefón que contesta, una vitrola que llora viejos tangos de mi flor $y$ un gato de porcelana
}

\author{
'pa que no maulle el amor. \\ ¡Y todo a media luz, \\ qué brujo es el amor! \\ A media luz los besos, \\ a media luz los dos.
}

y que posiblemente le trae al protagonista recuerdos de veladas similares. Aunque la oración aparece traducida fielmente en las versiones inglesa y francesa de esta novela, aunque se mantiene en ellas ese mismo valor deíctico, el lector extranjero no capta la asociación que establece Almanza, por desconocer la referencia al mencionado tango.

Algo parecido tiene lugar con el intertexto, es decir el conjunto de las relaciones que se ponen de manifiesto en el interior de un texto determinado, y que lo acercan tanto a otros textos del mismo autor como a otros textos literarios (Arrivé en Marchese/Forradellas 1986: 217). Como dice Roland Barthes, todo texto es un intertexto; otros textos están presentes en él ... bajo formas más o menos reconocibles (Barthes en Marchese/Forradellas ibid:217). Una vez más, es el extratexto, lo que sabe el lector de su cultura, lo que le permite identificar un elemento intertextual, sentirse destinatario del guiño que le hace el autor al incluir en su obra un elemento críptico para el que no comparta sus mismas coordenadas culturales.

En Sobre héroes y tumbas, vemos a Martín caminar por el Riachuelo, es decir, la desembocadura del Río de la Plata, y recordar a su perro, Bonito, aplastado por un camión frigorífico en esa misma zona. Y leemos: $Y$ de pronto ... también recordó un verso: no de Dante ni de Homero sino de un poeta tan callejero y tan bumilde como el Bonito. Dónde estaba Dios cuando te fuiste, se babia preguntado aquel desdichado (SHT:485). Este texto aparece en inglés como: He also remembered a verse: not one from Dante or Homer, but from a poet who was as fond of wandering the streets and as humble as Bonito. Where was God when you went away? that poor wretch bad asked himself (OHT:458-459), en italiano, 
ricordò anche un verso: non de Dante né di Omero, ma di un poeta non meno umile di Bonito. Dov'era Iddio quando te ne andaste, si era chiesto quell'infelice (SET: 355 ), y en francés, il se rappela un vers, qui n'etait pas de Dante ni d' Homère mais d'un poìte aussi vagabond et humble que Bonito. Où etait Dieu quand tu t'es en allée? s'etait demandé ce malbereux (A:360). La pre-

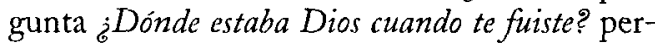
tenece al tango Canción desesperada, de Enrique Santos Discépolo (un poeta tan callejero y bumilde como el Bonito). Este guiño de Ernesto Sábato al lector de su novela sólo lo puede captar el lector nativo - ¿o habría que decir un cierto lector nativo de cierta edad, amante del tango?- o un determinado lector extranjero, posiblemente también de una cierta edad y aficionado al tango, que inmediatamente reconocen los versos de Canción desesperada e identifican al querido Discepolin bajo la alusión a un poeta callejero y humilde.

$\mathrm{Si}$, como se dijo al principio, el contexto cultural es el que permite desambiguar elementos oscuros o aquellos que pasan inadvertidos al lector que no comparte las mismas coordenadas culturales que el lector nativo, convendría entonces recordar la distinción entre cultura y civilización, puesto que nos resulta aquí de gran ayuda. Se entiende por civilización el conjunto de ideas, creencias, técnicas, arte y costumbres compartidas por un grupo humano. Pero, si bien el lector argentino, inglés, italiano y francés pertenecen a lo que se llama civilización occidental en tanto y en cuanto comparten unas características comunes, no podemos decir que compartan la misma cultura, ya que una cultura presupone elementos netamente localizados en tiempo y espacio (Santoyo 1994:14I). La cultura tiene que ver con lo individual, local y peculiar de una colectividad bumana cualquiera, con caracteristicas espaciales y temporales bien delimitadas, mientras que civilización, en cambio, apuntaría sobre todo a una condición supra o internacional y una amplia variedad de subsistemas culturales que coexistirian uno junto a otro, e incluso se solaparian (Santoyo ibid).

Esta distinción es de enorme utilidad a la hora de traducir, especialmente en el caso de literatura muy marcada culturalmente, como la que nos interesa. En ocasiones, nos encontramos con problemas de equivalencia, ya que en la cultura meta y en la lengua meta no existen términos para algo que es propio de la cultura argentina. Así ocurre, por ejemplo, con la traducción de al tipo carpincho (HCF:I27) o quebrada y corte (EIB:I9), que se refieren a un tipo de animal americano y a una forma de bailar el tango (con quebrada y corte) respectivamente. El primer ejemplo es traducido al italiano como al tipo roditore, al inglés como to the rodent variety, $\mathrm{y}$ al francés como au type raton laveur, todas ellas traducciones incorrectas por haber tomado en consideración sólo un elemento del análisis componencial del término carpincho como es el considerarlo un tipo de roedor. Un análisis componencial más amplio, sumado al conocimiento de otras características de este animal, habrian llevado a los traductores a entender que el autor quería decir que el personaje en cuestión tenía el pelo tieso, como de hecho lo tiene el carpincho. El segundo ejemplo aparece en italiano como le figure piit ardite del tango, en inglés como suggestive dance steps, y en francés como certaines figures de tango. También aquí se trata de traducciones incorrectas, pues lo que se desprende para el lector nativo es que el relato no se desarrolla en un salón, donde no está bien visto que se baile el tango de esta manera, e incluso, que se trata de un hecho lejano en el tiempo, allá por la década de 1920 o I930 a lo sumo. Estos términos se disfrutan en monopolio por la sociedad que les ha dado origen (Santoyo ibid) -en este caso la argentina- $y$, por ende, carecen de parangón fuera de la misma. En otras ocasiones, no hallamos una falta de equivalencia léxica sino una imposibilidad de aprehender la connotación implícita en un texto por carecer

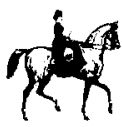

99 
争

100 el lector foráneo de las coordenadas culturales necesarias para ello. Por ejemplo, cuando leemos en Sobre béroes y tumbas que dos personajes, Martín y Alejandra, van a un café del Bajo y se sientan a una mesa que da al Paseo Colón, el lector argentino recuerda el tango que dice en un viejo café del Paseo Colón, donde van los que tienen perdida la $f e$, como estos personajes, $y$ sabe que el Bajo fue una zona de mal vivir. Además, Martín y Alejandra son dos seres a la deriva y el Bajo es una zona de Buenos Aires situada junto al Río de la Plata. Todo esto se le escapa al lector foráneo, a menos que acceda a la novela con el bagaje cultural que trae consigo el lector nativo.

Podemos resumir diciendo que las categorías de código, emisor, receptor y contexto son cómodas etiquetas para identificar algunos de los componentes del proceso de comunicación en general y de la comunicación lingüística en particular, pero que, cuando dichas categorías se aplican a la comunicación lingüistica se puede constatar que son mucho más complejas de lo que pudiera parecer a simple vista. $\mathrm{La}$ dificultad se acrecienta cuando se analizan en una obra literaria, y más aún cuando se trata de una obra literaria traducida a otra lengua y, por ende, a otra cultura, pues hay que tener presente de qué código en concreto estamos traduciendo, cuál es el emisor original del mensaje y cuál su destinatario primero, así como el contexto situacional y cultural que desambigua y permite entender el mensaje en toda su extensión. De no hacerlo estaremos empobreciendo la obra literaria, cuando no ofreciendo una versión mínima (cf. Nida) de la misma, o, lo que es más grave, distorsionando el mensaje original.

RECIBIDO EN SEPTIEMBRE DE 2000

\section{BIBLIOGRAFÍA}

Bobes Naves, M. del Carmen (1974), Teoría general de la novela, Madrid, Gredos.

Bobes Naves, $\mathrm{M}$. del Carmen, «El personaje novelesco: cómo es, cómo se construye», en Mayorial M. (coord.) (1990), El personaje novelesco, Madrid, Cátedra-Ministerio de Cultura.

Cortázar, J. (1970), Relatos, Buenos Aires: Ed. Sudamericana.

Fasold, R. (1984), The sociolinguistics of society, Oxford: Basil Blackwell.

González, E. (1986), Ascenso y caída del peronismo, Buenos Aires: Ed. Antídoto.

Hudson, R. (1980), Sociolinguistics, Cambridge: Cambridge University Press.

Hymes, D. (1974), Foundations of sociolinguistics, Londres: Travistock.

Krysinski, W. (r977), Encrucijada de signos, Madrid: Arco Libros.

Lázaro Carreter, F. (1997), El dardo en la palabra, Madrid: Círculo de Lectores.

Marchese A. y Forradellas J. (1986), Diccionario de retórica, critica y terminologia literaria, Barcelona: Ariel, Barcelona.

Santoyo Mediavilla, J.C. (1994), «Traducción de cultura, traducción de civilización» en Hurtado Albir, A. ed. Estudios sobre la traducción, Castellón: Universidad Jaume I.

Steiner, G. (1976), After Babel, Nueva York: Oxford University Press.

\section{OBRAS LITERARIAS CITADAS Y SUS RESPECTIVAS}

TRADUCCIONES AL INGLÉS, ITALIANO Y FRANCÉS

Bioy Casares, Adolfo

1985. La aventura de un fotógrafo en La Plata, Madrid: Alianza.

I991. The adventure of a photographer in La Plata, translated by Suzanne Jill Levine, Londres: Bloombsbury.

199i. Un photograph à La Plata, traduit par André Gabastou et María Inés Pavesi, Paris: Christian Bourgois Editeur.

Borges, Jorge Luis

1982. El informe de Brodie, Madrid: Alianza Emecé. [1970] 
1976. Doctor Brodie's report, translated by Norman Thomas di Giovanni in collaboration with the author, Londres: Penguin.

I994. Il Manoscritio di Brodie, traduzione di Livio Bacchi Wilcock, en Borges, Tutte le Opere, Milan: Mondadori.

I972. Le rapport de Brodie, traduit par FrançoiseMaric Rosset, Paris: Gallimard.

Cortázar, Julio

I983. Histortas de cromopios y de famas, Madrid: Alfaguara. [Ig62]

I994. Cronopios and famas, translated by Paul Blackburn, Londres: Marion Boyards.

197. Storie di cronopios e di fama, traduzione di Flaviarosa Nicoletti Rossini, Torino: Einaudi.

1977. Cronopes et famenx, traduit par Laure GuilleBatallion, Paris: Gallimard.

Sabato, Ernesto

I984. Sobre béroes y tumbas, Madrid: Seix Barral. [1961]
1990. On beroes and tombs, translated by Helen Lane, Londres: Jonathan Cape.

1993. Sopra eroi e tombe, traduzione di Fausta Leoni, Roma: Editori Reuniti.

1967. Alcjandra, traduit par Jean-Jacques Villard,

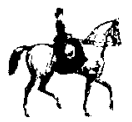

Paris: Editions du Seuil.

Soriano, Osvaldo

1987. No babrá mäs penas ni olvido, Barcelona: Ediciones B. 1986. A fumny divty little war, translated by Nick Caistor, Londres: Readers International. 1979. Mai piti pene né oblio, traduzione di Angelo Morino, Torino: Einaudi.

1980. Jamais plus de peine ni d'oubli, traduit par Marie France de Palomera, Paris: Fayard.

Vázquez Rial, Horacio

1989. Historia del Triste, Barcelona: Plaza y Janés. [1987]

1990. Triste's Story, translated by Jo Labanyi, Londres: Readers International. 
